Review

\title{
Trichothecenes in Cereal Grains
}

\section{Nora A. Foroud ${ }^{1,2}$ and François Eudes ${ }^{1, *}$}

1 Lethbridge Research Centre, Agriculture and Agri-Food Canada, $54031^{\text {st }}$ Avenue South, Lethbridge, AB, Canada T1J 4B1. E-Mail: nora.foroud@agr.gc.ca

2 Michael Smith Laboratories, The University of British Columbia, \#301 - 2185 East Mall, Vancouver, B.C., Canada V6T 1Z4

* Author to whom correspondence should be addressed; E-Mail: francois.eudes@agr.gc.ca; Tel. +1-403-327-4561; Fax: +1-403-382-3156

Received: 7 November 2008; in revised form: 16 December 2008 / Accepted: 5 January 2009 / Published: 6 January 2009

\begin{abstract}
Trichothecenes are sesquiterpenoid mycotoxins associated with fusarium head blight (FHB) of cereals, with worldwide economic and health impacts. While various management strategies have been proposed to reduce the mycotoxin risk, breeding towards FHB-resistance appears to be the most effective means to manage the disease, and reduce trichothecene contamination of cereal-based food products. This review provides a brief summary of the trichothecene synthesis in Fusarium species, their toxicity in plants and humans, followed by the current methods of screening and breeding for resistance to FHB and trichothecene accumulation.
\end{abstract}

Keywords: Trichothecene; fusarium head blight; cereal grain.

\section{Introduction}

Fusarium head blight (FHB) is a destructive disease of cereal grain crops, with worldwide economic impact. The disease is caused by a series of trichothecene-producing Fusarium species, of which $F$. graminearum (teleomorph: Gibberella zeae) and F. culmorum are the most economically relevant [1,2]. Trichothecenes are sesquiterpenoid mycotoxins that have been implicated in disease aggressiveness [4-6] and are found to accumulate in kernels of infected spikelets, rendering the grain unsuitable for human or animal consumption. Ingestion of contaminated grain can cause intestinal 
irritation in mammals, and can lead to feed refusal in livestock [7]. A few outbreaks of alimentary toxic aleukia (ATA), a potentially fatal condition caused by trichothecene ingestion, have been reported in human societies as far back as the $18^{\text {th }}$ century (see Section 2.2). The main source of mycotoxins in the food chain is Fusarium-contaminated grain, usually from FHB-outbreaks, although some species may proliferate on grain during storage. The first documented FHB-outbreak occurred in England in 1884, where the disease was named "wheat scab" [8]. Outbreaks have since been reported in the Americas [9-11], Asia [12, 13], Australia [14], Europe [1, 15], and South Africa [16, 17]. The most notorious epidemic in North America spanned the 1990s, where in the United States alone, estimated economic losses approached 3 billion USD [18]. In South Africa, a double cropping system (with maize as a summer crop and wheat as a winter crop) in combination with conservation tillage has led to a growing FHB problem, especially in regions where irrigation is required [16]. Rice-wheat rotations are routine in many Asian countries. Both rice and wheat are host-crops, and while FHB is more endemic in the latter, the former still serves as a host for innoculum buildup [18]. FHB of barley and wheat is a pervasive problem in China. Between 1951 and 1990, wheat farmers were burdened with seven severe epidemics (exceeding $40 \%$ yield losses) and 14 moderate epidemics (10-20\% yield losses) [12]. The subsequent introduction of moderately resistant cultivars has coincided with a reduced frequency of severe epidemics [20].

FHB-management strategies are essential for reducing the economic damages and potential health hazards associated with this disease. Strategies have been developed to target each of the three components (innoculum source, susceptible host, and favorable environmental conditions) which are necessary for an outbreak. Innoculum source is usually present in the form of ascospores in the soil. Studies have shown that crop-rotation, tillage, chemical or biological control, and the use of FHBresistant cultivars can all contribute to reduce the amount of innoculum harbored in the soil by reducing the amount of Fusarium/Gibberella-contaminated crop and/or crop debris [21-27]. The second essential component for an outbreak is a suitable host for the spores to germinate and establish disease. In order to reduce the impact of this disease, we need to convince farmers to grow resistant cultivars. The selection of registered cultivars with decent FHB-resistance is limited. Moreover, farmers preferentially select cultivars with good agronomics, which often have poor resistance. Finally, the third component necessary for disease establishment: favorable environmental conditions. FHB thrives in wet, humid conditions with an optimum temperature of $25^{\circ} \mathrm{C}$ during anthesis and grain filling stages of crop development [1]. While the weather cannot be controlled, disease forecasting models can be used to devise an effective spraying schedule for chemical control, and for more organized post-harvest management of potentially diseased kernels [10, 19, 28-29]. Application of more than one management strategy [30] has been shown to be most effective in reducing FHB severity and trichothecene accumulation in grains. However, if we had to focus our efforts on only one disease management strategy, the development of highly resistant cultivars, with good agronomic qualities, would have the largest impact. The use of resistant cultivars can manage each of the three components essential for disease. First, it can reduce the amount of inoculum buildup in host-crop debris (and subsequently in the soil). Second, short of only cultivating non-host crops, we can reduce the suitability of host-crops by using highly-resistant cultivars. Finally, while a strong genotypeenvironment interaction has been observed in FHB disease outcomes [31], studies have shown that the effect of the environment can be indirectly managed by using highly-resistant genotypes. In contrast, 
while genotypes with moderate or intermediate resistance can reduce the impact of FHB, this resistance is not stable under high disease pressure.

In a two-year FHB field trial of winter wheat, rye and triticale genotypes, grown in three regions of South-West Germany, Miedaner et al. (2001) observed strong interactions between genotype and disease outcomes/trichothecene accumulation [31]. They also observed a significant impact of the environment on these interactions, but the effect of the environment was reduced in more resistant genotypes. We observed a similar phenomenon between wheat-genotypes and their interaction with different F. graminearum trichothecene-chemotypes (chemotype meaning the major trichothecene produced by a given strain) [32]. Trichothecene-chemotype played a role in disease spread and in the development of Fusarium damaged kernels (FDK) in intermediate/moderate sources of resistance, but the effect of chemotype was not observed in susceptible and resistant genotypes. High levels of resistance or susceptibility were stable across all chemotypes tested [32]. We also found that while the 3-O-acetyl 4-deoxynivalenol (3ADON) chemotypes led to the highest disease symptoms in intermediate/moderate resistant sources, FDK in plants infected with 3ADON-producers was nearly as low as the least aggressive chemotype, nivalenol (NIV). But, again, in highly resistant sources, the aggressiveness of the isolate and the FDK did not impact disease outcomes.

These studies emphasize the importance of developing highly resistant cultivars. The level of resistance "is more important in governing [4-deoxynivalenol (DON)] accumulation in a given cultivar than is the aggressiveness of an isolate [33]". In this review, we will begin with an overview of trichothecenes to emphasize their impact on FHB-disease outcomes and on human health. This will be followed by a section on FHB-resistance, sources and current breeding methods. Finally, we will conclude with our recommendations of the direction breeding programs should take in order to have the highest impact on reducing FHB of grain crops and trichothecene accumulation in the food chain.

\section{Trichothecenes}

\subsection{Trichothecene biosynthesis and structure}

Trichothecenes are toxic sesquiterpenoid compounds composed of a central core of fused cyclohexene/tetrahydropyran rings. In addition, a cyclopentyl moiety is also fused to the tetrahydropyran ring through C-2 and C-5. Furthermore, C-12 comprises part of an epoxide functionality (Figure 1), which has been deemed crucial for toxicity [34]. There are five positions at which functionality varies, most commonly featuring hydroxyl or acetyl groups. Four types of trichothecenes have been identified from trichothecene-producing fungi: types A, B, C and D. The major type A trichothecenes in Fusarium species include T-2 toxin (T-2) and HT-2 toxin (HT-2), both of which posses an isovalerate function at C-8 [35]. F. sporotrichiodies and F. poae are some of the major type A trichothecene producers [36]. Type A trichothecenes are highly toxic; T-2 has been reported to be roughly ten times more toxic in mammals than DON [37]. DON is the most prevalent toxin associated with FHB, and belongs to the more phytotoxic [3] type B trichothecenes which feature a ketone at C-8 [35]. F. culmorum and F. graminearum produce mainly DON, NIV and their derivatives [36]. Type $\mathrm{C}$ and $\mathrm{D}$ trichothecenes, respectively characterized by a second epoxide (C-7,8 or C-9,10) or an ester-linked macrocycle $(\mathrm{C}-4,16)$, are not associated with FHB [38]. Other mycotoxins, such as zearelenone (ZON), fumonisins, moniliformin and butenolide are also produced 
by Fusarium species [35, 39-40]. The trichothecene biosynthesis pathway is summarized in Scheme 1; genes associated with trichothecene production are presented in Table 1. The initial substrate, farnesyl pyrophosphate, is cyclized into a non-toxic trichothecene product, trichodiene. This step is catalyzed by trichodiene synthase, TRI5 [6, 34, 41]. A multifunctional cytochrome P450 monooxygenase, TRI4, catalyzes the next four steps in the pathway: C-2 hydroxylation [42-43], followed by 12,13 epoxidation and two more hydroxylation reactions [43]. The final product of TRI4 activity, isotrichotriol, undergoes two non-enzymatic isomerization steps [44], including a cyclization whereby $\mathrm{C}-\mathrm{O}$ bond formation occurs between the C-2 oxygen and C-11. The product, isotrichodermol, forms the skeleton trichothecene structure, and is acetylated by TRI101 at C-3 [45], and hydroxylated by TRI11 at C-15 to produce 15-deacetylcalonectrin [46]. 15-deacetylcalonectrin can act as a substrate for DON production, by hydroxylation of C-3 and C-7 and the addition of a ketone group at C-8. Alternatively, it can be acetylated by the activity of TRI3 at C-15 to produce calonectrin [47].

Figure 1. Type $A$ and $B$ trichothecene structures. Examples of type A trichothecenes include T-2 toxin (T-2), HT-2 toxin (HT-2), 4,15-diacetoxyscirpenol (4,15-DAS). Examples of type B trichothecenes include nivalenol (NIV), 4-deoxynivalenol (DON), 3$O$-acetyl DON (3-ADON), and 15-O-acetyl DON (15-ADON). OAc = acetyl function; OIsoval $=$ isovalerate function.

\begin{tabular}{lccccc}
\hline Toxin & R1 & R2 & R3 & R4 & R5 \\
\hline DON & $-\mathrm{OH}$ & $-\mathrm{H}$ & $-\mathrm{OH}$ & $-\mathrm{OH}$ & $=\mathrm{O}$ \\
3-ADON & $-\mathrm{OAc}$ & $-\mathrm{H}$ & $-\mathrm{OH}$ & $-\mathrm{OH}$ & $=\mathrm{O}$ \\
15-ADON & $-\mathrm{OH}$ & $-\mathrm{H}$ & $-\mathrm{OAc}$ & $-\mathrm{OH}$ & $=\mathrm{O}$ \\
NIV & $-\mathrm{OH}$ & $-\mathrm{OH}$ & $-\mathrm{OH}$ & $-\mathrm{OH}$ & $=\mathrm{O}$ \\
T-2 & $-\mathrm{OH}$ & $-\mathrm{OAc}$ & $-\mathrm{OAc}$ & $-\mathrm{H}$ & $-\mathrm{OIsoval}$ \\
HT-2 & $-\mathrm{OH}$ & $-\mathrm{OH}$ & $-\mathrm{OAc}$ & $-\mathrm{H}$ & $-\mathrm{OIsoval}$ \\
4,15-DAS & $-\mathrm{OH}$ & $-\mathrm{OAc}$ & $-\mathrm{OAc}$ & $-\mathrm{H}$ & $-\mathrm{H}$ \\
\hline
\end{tabular}

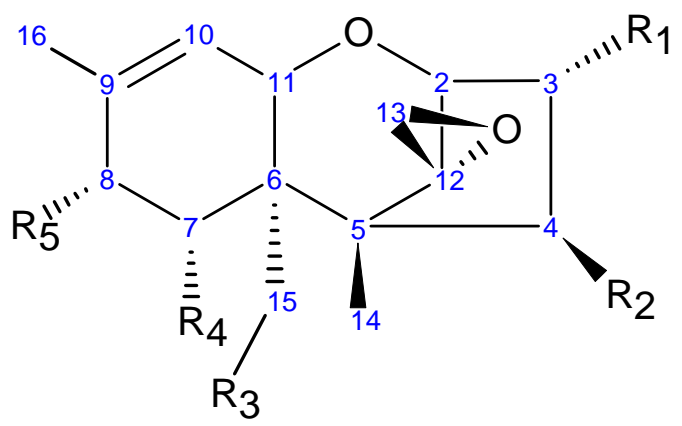

Calonectrin serves as a substrate for the biosynthesis of acetylated DON and NIV products, including 3,15-diacetyldeoxynivalenol (3,15-ADON), 15-acetyldeoxynivalenol (15-ADON), and 4acetylnivalenol (4-ANIV). Functional expression of F. graminearum Tri7 and Tri13 genes is necessary for NIV-chemotypes of this species-the absence of these genes confers DON-chemotypes [48-49]. NIV can be synthesized directly from DON, or by conversion of calonectrin to 3,15diacetoxyscirpenol (-DAS) and then to NIV by ketone addition at C-8. 3,15-DAS is also the major substrate type A trichothecenes. Functional expression of F. sporotrichioides Tri7 and Tri8 produces T-2 toxin chemotypes in this species [50]. C-4 acetylation of 3,15-DAS (catalyzed by TRI7) produces 3,4,15-triacetoxyscirpenol, which can be converted to 4,15-DAS by TRI8, or serves as substrate for T2 toxin synthesis, initiated by TRI1. HT-2 toxin accumulates in the absence of TRI7, via hydroxylation and isovalerate addition to C-8 of 3,15-DAS. 
Table 1. Genes involved in trichothecene production. For more details on trichothecene gene cluster see [163, 167-170]. Note that recent analyses have revealed that Tri1 and Tri101 are in the core-trichothecene gene cluster (core-Tri) in F. equiseti and F. scirpi (R. Proctor, unpublished).

\begin{tabular}{|c|c|c|c|}
\hline Gene & Cluster & Description & References \\
\hline \multicolumn{4}{|c|}{ Enzymes: for pathway reactions see also Scheme 1} \\
\hline Tri1 & Tri1-Tri16 & $\begin{array}{l}\text { C-7 monooxygenase ( } F \text {. graminearum); C-8 monooxygenase ( } F \text {. } \\
\text { graminearum, F. sporotrichioides) }\end{array}$ & $\begin{array}{l}{[154-156,174-} \\
175]\end{array}$ \\
\hline Tri3 & Core Tri & 15-O-acetyltransferase & [47] \\
\hline Tri4 & Core Tri & monooxygenase & {$[41-42,157]$} \\
\hline Tri5 & Core Tri & sesquiterpene cyclase, 'trichodiene synthase' & {$[6,40,158]$} \\
\hline Tri7 & Core Tri & $\begin{array}{l}\text { 4-O-acetyltransferase; functional F. graminearum TRI7 required for } \\
\text { NIV-chemotype; functional F. sporotrichioides TRI7 required for T-2 } \\
\text { toxin production }\end{array}$ & [49-50] \\
\hline Tri8 & Core Tri & $\begin{array}{l}\text { C-3 deacetylase; functional F. sporotrichioides TRI8 required for T-2 } \\
\text { toxin production }\end{array}$ & {$[50,159]$} \\
\hline Tri9 & Core Tri & & {$[50]$} \\
\hline Tri11 & Core Tri & C-15 monooxygenase & {$[45,160]$} \\
\hline Tri13 & Core Tri & $\begin{array}{l}\text { monooxygenase; functional } F \text {. graminearum TRI13 required for NIV- } \\
\text { chemotype }\end{array}$ & {$[49,161]$} \\
\hline Tri14 & Core Tri & & \\
\hline Tri16 & Tri1-Tri16 & & {$[162]$} \\
\hline Tri101 & None & 15-O-acetyltransferase & {$[44,136,162]$} \\
\hline \multicolumn{4}{|c|}{ Transcription Factors } \\
\hline Tri6 & Core Tri & $\begin{array}{l}\text { zinc-finger DNA binding protein; required for T-2 toxin production; } \\
\text { binding motif (YNAGGCC) found in most promoter regions within } \\
\text { Tri5 cluster }\end{array}$ & {$[164,165,50]$} \\
\hline Tri10 & Core Tri & & {$[166]$} \\
\hline \multicolumn{4}{|l|}{ Other } \\
\hline Tri12 & Core Tri & $\begin{array}{l}\text { major facilitator superfamily (MFS) transporter involved in } \\
\text { trichothecene efflux }\end{array}$ & {$[166,141]$} \\
\hline
\end{tabular}

\subsection{Trichothecene Toxicity: Food Safety and Quality}

Trichothecene exposure can lead to growth retardation in eukaryotes, causing reproductive dysfunction in mammals and inhibition of seedling growth/regeneration in plants (reviewed in [51]). The toxicity of trichothecenes is attributed to their ability to inhibit peptidyl transferase activity of 60S ribosomes [52]. Additional impacts of trichothecene toxicity (reviewed in [51, 53, 54] include disruption of nucleic acid synthesis [55, 56], mitochondrial function [55, 57], membrane integrity [58, 59], and cell division. Trichothecenes have been shown to induce apoptosis in animal cells [60-62], and may induce programmed cell death in plants [51]. 
Scheme 1. Trichothecene biosynthesis pathways. Steps in the pathway are catalyzed by Tri-gene products (see Table 1 for more details), and have been identified in either $F$. graminearum (Fg), F. sporotrichioides (Fs), or both. OAc = acetyl function; IsovalO = isovalerate function. Diagram is modified from [33, 50, 169, and 172].

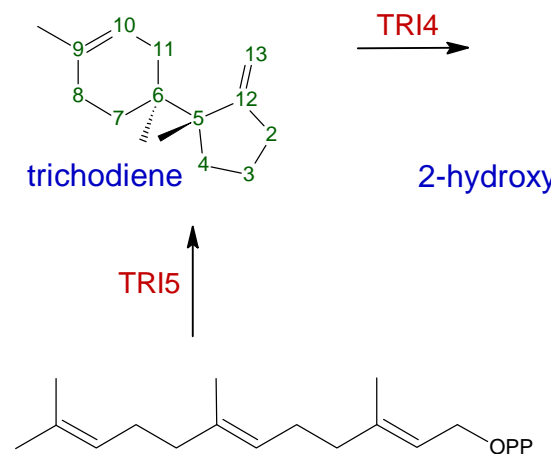

farnesyl-pyrophosphate
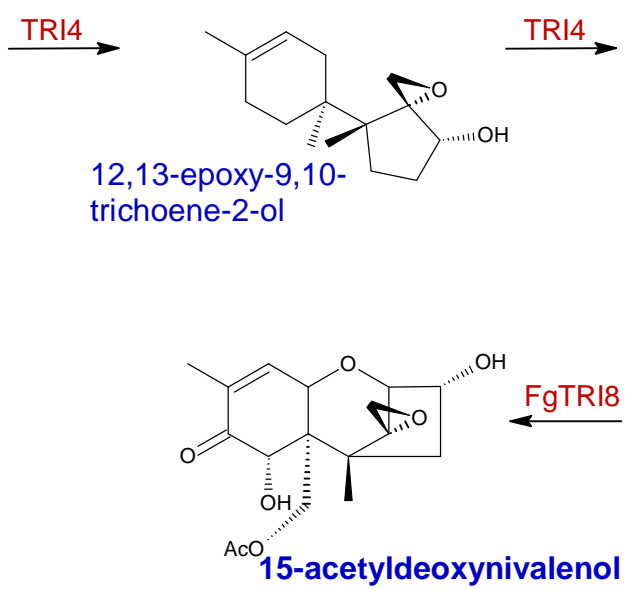

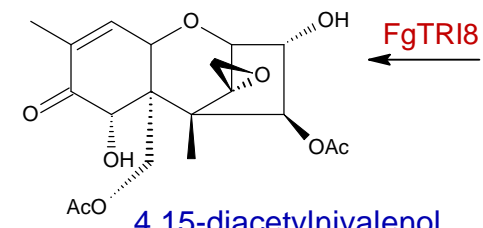

$\mathrm{AcO}$ 4,15-diacetylnivalenol

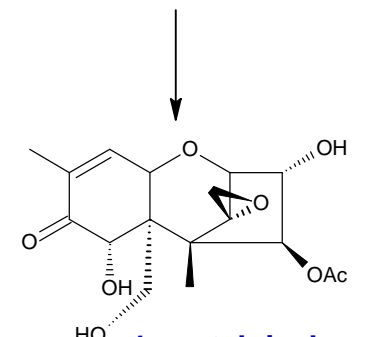

HO 4-acetylnivalenol

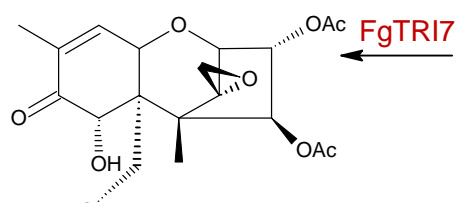

AcO $3,4,15$-triacetylnivalenol

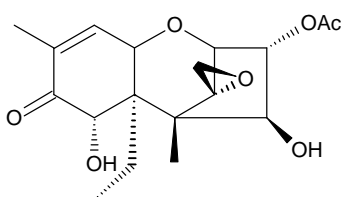

AcO 3,15-diacetylnivalenol

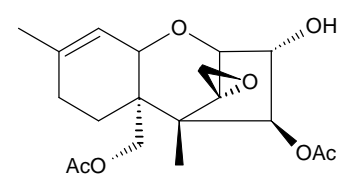

4,15-diacetoxyscirpenol

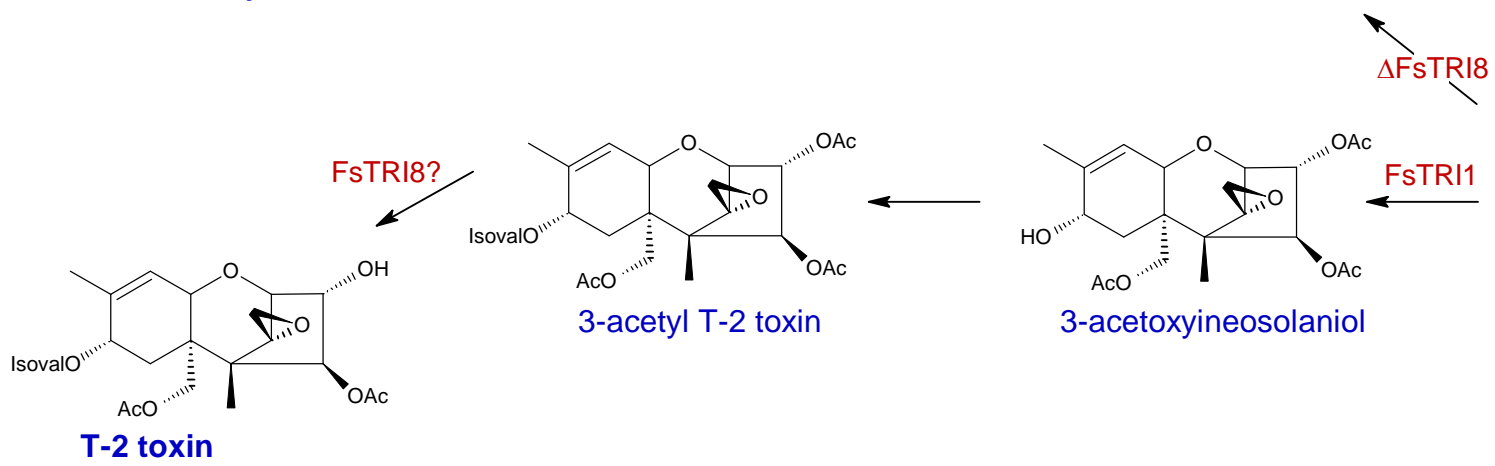

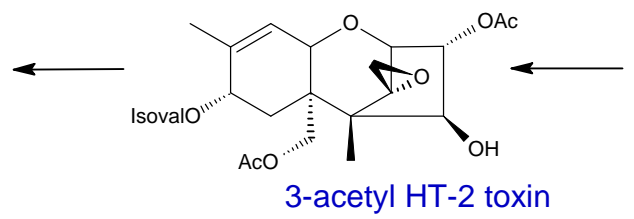


Scheme 1. Cont.

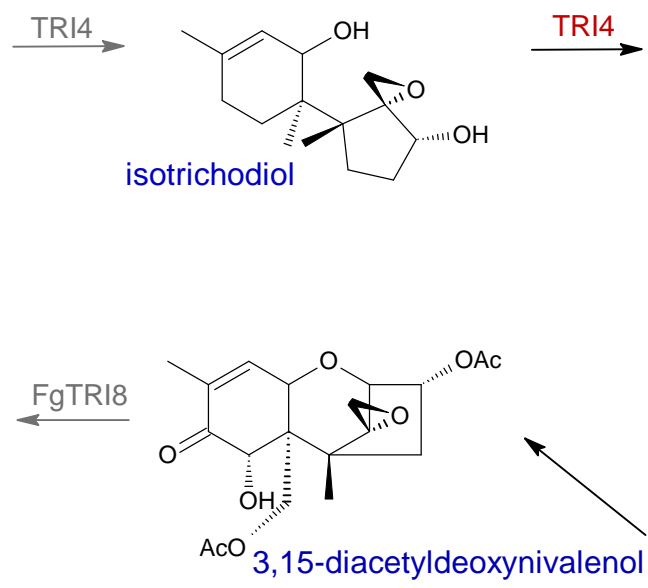

FgTRI13

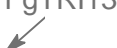

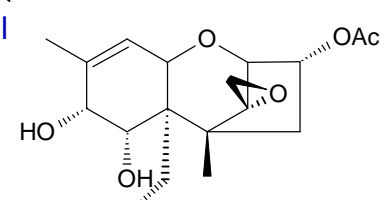

$\mathrm{AcO}$

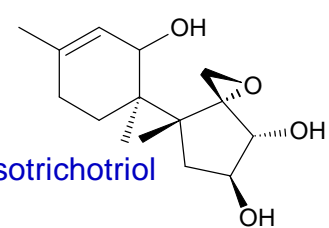

7,8-dihydroxycalonectrin
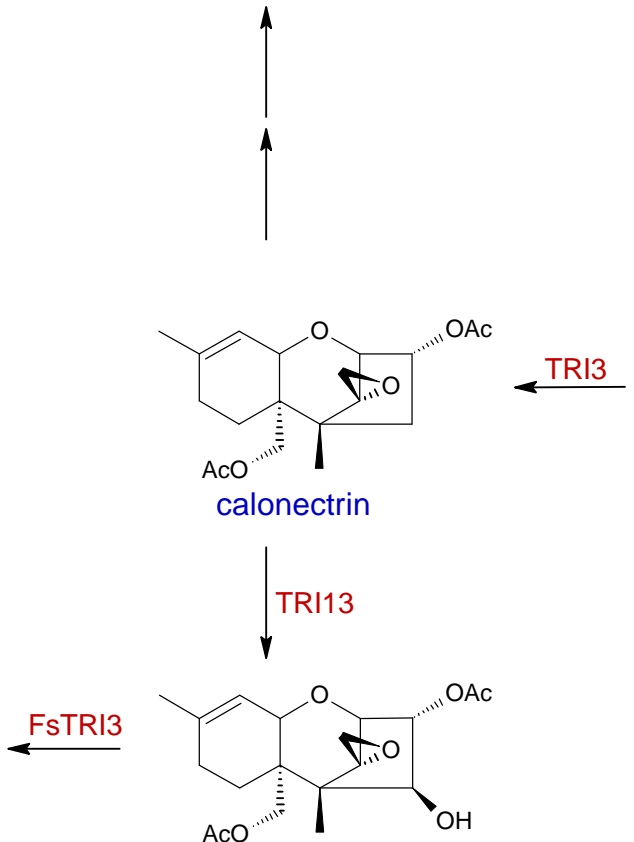

AcO 4,15 -triacetoxyscirpenol $\triangle$ FsTRI7
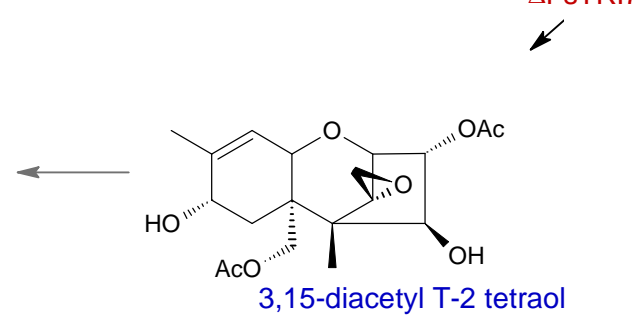

TRI13

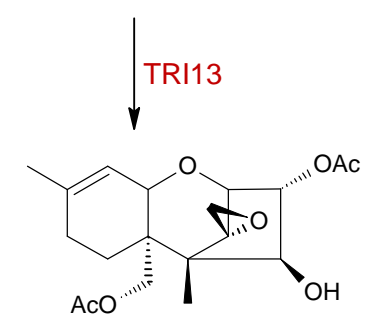

3,15-diacetoxyscirpenol
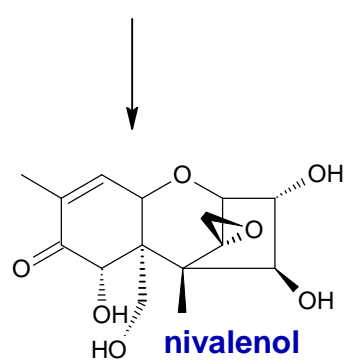

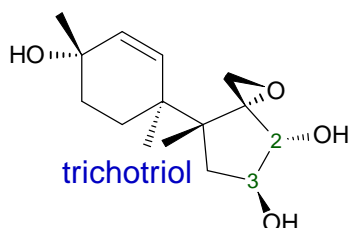<smiles>[3H][3H]</smiles><smiles>CC1=CC2OC3=C[C@H](O)[C@@H](C[C@H]3C)[C@@]2(C)CC1</smiles>

isotrichodermol TRI101

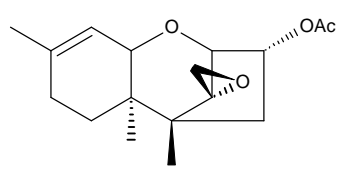
isotrichodermin TRI11

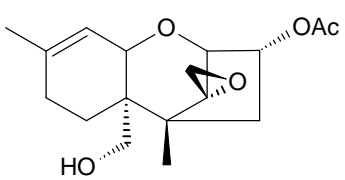

15-deacetylcalonectrin

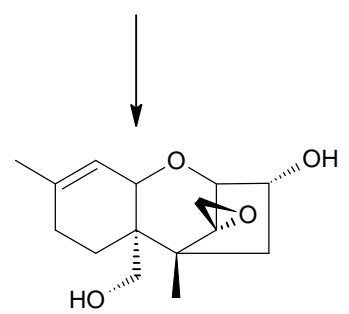

3,15-dideacetylcalonectrin

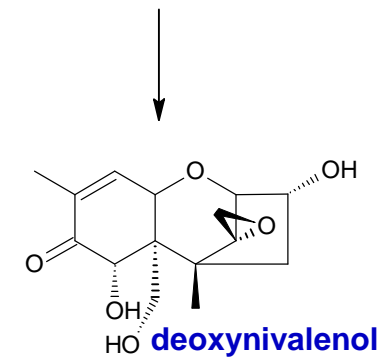


It is pertinent that regulations be put into place to control the allowable quantities of trichothecenes entering the food chain. Ingestion of contaminated grain can cause alimentary toxic aleukia (ATA); a condition characterized by an initial stage of intestinal irritation causing emesis and diarrhea, followed by aleukia and anemia, and which may ultimately lead to death. The first recorded Fusarium-related ATA outbreak occurred in Siberia in 1913, but the human impacts of ATA may go as far back as the 1730s, when symptoms of a reported disease epidemic in New Hampshire are reminiscent of ATA (reviewed in [8]). The most devastating outbreak occurred in Russia between 1942 and 1948, where at least 100,000 people died. In this case, over-wintered grain had become contaminated with T-2 producing $F$. sporotrichioides or F. poae, during mild winters [63, 64]. It was not until 1950 that the connection between Fusarium toxins and ATA was established.

The most abundant source of trichothecene contamination in cereal grains today is due to FHB, which is primarily caused by type-B trichothecene-producers. Trichothecene accumulation occurs when spikes are infected during or post-anthesis [65], although significant yield losses are more relevant in early infections (anthesis to early stages of kernel development) [66-67]. Trichothecenecontaminated grain is readily distinguished owing to its shriveled and discolored appearance. Several studies have shown that percentage of Fusarium damaged kernels (FDK) serves as a reliable estimate of DON content [31, 33]. This allows for rapid visual screening of Fusarium damaged kernels (FDK) in order to prevent contaminated grain entering the food chain in unsafe quantities-although FDK screening for toxin contamination should be used with caution since reduced physical damage is observed if infection occurs past the soft dough stages of kernel development $[65,68]$. FDK can be used as a preliminary screen when sorting and grading grain, but quantitative trichothecene testing is advisable before the grain enters the food chain. In Canada, maximum FDK limits are in place for different wheat classes and varieties, and are enforced by the Canadian Grain Commission at licensed grain elevators. DON-testing is carried out on end-products by the Canadian Food Inspection Agency and Health Canada to ensure the maximum allowable in quantity of this trichothecene in food-stuffs is not exceeded. Currently, the maximum limit of DON is set at $2 \mathrm{ppm}$ for Canadian soft wheat (1 ppm for use in baby food), and the establishment of maximum limits of DON in hard wheat is currently being evaluated (Tom Nowicki and Randy Clear, personal communications). The established DON limits are also being reviewed, and more rigid standards may be imposed to harmonize the standards with those of the European Union. DON tolerance in China, Hungary, Russia, Switzerland, and the United States is $1 \mathrm{ppm}$; and in Austria, Germany, and the Netherlands is 0.5 ppm [69]. Standards are also put into place for grain that is used in animal feed, as the trichothecenes cause similar ailments in farm animals as in humans [70].

\subsection{Trichothecenes as Aggressiveness Factors in Fusarium Head Blight}

Different levels of aggressiveness and pathogenicity have been observed in different isolates of a given Fusarium species. These differences can be attributed only in part to fitness, suggesting that aggressiveness factors may contribute to disease outcomes. Toxins have long been implicated as aggressiveness factors in pathogen systems. Examples include host selective toxins (HSTs), which are produced by the pathogen, are only toxic towards the target host, and are necessary for causing disease [reviewed in 71]. These include AK-toxin of Alternaria alternata, victorin of Cochliobolus victoriae, 
and T-toxin of $C$. heterostrophus, the causal agents in black spot of Japanese pear [72], Victoria blight of oats [73], and corn leaf blight [74], respectively. Other examples of toxins involved in pathogen aggressiveness or pathogenicity in plants include botryane of grey mould causing Botrytis cinerea [75] and zinniol of Alternaria species [76]. Over the past few decades, evidence of trichothecenes as nonHSTs involved in aggressiveness of Fusarium-related diseases has been accumulating. Observations by Beremand et al. (1991) suggested a link between trichothecene production, fertility and pathogenicity of F. sambucinum isolates [77]. Correlations between fungal biomass (measured by ergosterol quantification) and DON accumulation in cereal grains have been observed [31, 78-79]. A link between DON accumulation and disease outcomes has also been observed [68, 80]. The trichothecene-chemotype of isolates [32] and the cumulative impact of multiple trichothecenes produced either by a single isolate [81] or by a composite of isolates [82] may increase disease severity. In addition, some FHB-resistant sources have been shown to have the ability to detoxify DON, primarily by glycosylation [reviewed in 83]. Together, these data suggest that the ability of Fusarium species to cause disease is linked to trichothecene accumulation in the host, and that reduced aggressiveness may be observed by either reduced toxin production by the pathogen, or removal/degradation of the toxin by the host.

In 1995, Proctor et al. developed a trichothecene non-producing strain of F. graminearum (Tri5-; wild-type Tri5+), prepared by gene disruption of trichodiene synthase (Tri5) [6]. A series of studies have been conducted using these strains, in order to clarify the role of trichothecenes in FHBaggressiveness, and results are generally consistent with a role for trichothecenes in disease spread in Triticeae [3, 5-6, 84-85) and in maize [4]. Trichothecenes are not necessary for initial infection [84], or infection of the wheat fruit coat, but they are required for entry into the rachis and subsequently for disease spread [86]. In the absence of trichothecene-production, F. graminearum is shown to be contained in point-inoculated spikelets by cell wall thickening at the rachis node [86].

\section{Fusarium Head Blight Resistance}

\subsection{Mechanisms of Resistance}

FHB resistance is dominant and quantitative. A gene-for-gene resistance interaction has not been identified in FHB-resistance, and immunity to the disease has not been observed. Stability of resistance is dependent on environmental-factors at the time of infection and/or aggressiveness-factors associated with the invading Fusarium strain—although resistance has been shown to be stable in genotypes with very high levels of resistance [31-32, 87]. Several different forms of resistance have been identified (Table 2). These mechanisms of resistance can interact with each other to improve the overall resistance.

Due to the physiological differences between maize and other cereals, resistance in maize is described separately. Two major forms of resistance in maize include: (1) silk-resistance, where the fungus cannot penetrate the silk channel to infect the kernels [88]; and (2) kernel-resistance, where the fungus cannot penetrate the rachis, or 'cob', and hence does not spread from kernel to kernel [89]. These two forms of resistance in maize are somewhat similar to resistance to initial infection (type I) and disease spread (type II), respectively, in other cereal grains. Type I and type II resistances, first described by Schroeder and Christensen, are the best documented forms of resistance, since they are 
the most readily ascertained [90]. Type I resistance can be measured as the percentage of spikelets exhibiting symptoms upon exposure to the pathogen. Plants are typically sprayed during anthesis with macroconidial (or ascosporic) suspensions and high-humidity is maintained (by bagging infected heads or by mist-irrigation) for a few days after inoculation. Alternatively, the grain spawn method, where infected wheat or corn is dispersed in the field, can be used to better mimic natural conditions of infection [91-92]. Resistance is measured 7 to 21 days after anthesis, typically reported as a 'disease index', where 'incidence' (percentage of diseased spikes) is multiplied by 'severity' (percentage of infected spikelets on diseased spikes). Acquiring accurate assessments of type I resistance is impeded by several factors: (a) the amount of inoculum that actually reaches the spikelets is immeasurable, resulting in variability in the exposure of different spikes or plants within and between experiments; (b) environmental conditions are difficult to control, especially in field experiments; and (c) 'disease index' is not a measure of type I resistance alone, but rather a combination of resistance to initial infection, disease spread and tolerance [92-93]. Some researchers equate 'incidence' with type I resistance and 'severity' with type II resistance, while others equate 'disease index' as an estimate of both type I and II resistances [92]. These inconsistencies in evaluation standards stress the need to review our definition of type I resistance, as is proposed by Mesterházy [94].

Evaluation of type II resistance is a little more straightforward [92]. A quantifiable amount of inoculum is injected into individual spikelets at anthesis, and high-humidity maintained for several days. Resistance is measured as the number of infected spikelets below the inoculation point; note that the disease typically spreads down the spike through the rachis. Delayed hyphal colonization of the vascular bundles in the rachis is observed in type II resistant genotypes [95]. Recent work presented by Ilgen et al. shows that trichodiene synthase expression is induced when the growing hyphae comes in contact with the ovaries [96]. It is likely that metabolite(s) present in the ovaries induces expression of trichothecene synthesis. We already know that trichothecenes are necessary for disease spread [3, 5-6, 84], but they do not appear to play a role in establishing initial infection by spray or point inoculation [84]. The data presented by Ilgen et al. effectively demonstrates that trichothecene synthesis does not begin until the fungus has successfully invaded the spikelet [96]. In other words, trichothecenes, which are necessary for disease spread, do not accumulate until after initial infection has been established.

If trichothecenes are not necessary for establishing initial infection, and since evaluation methods for resistance to initial infection is confounded by resistance to disease spread, then perhaps a more accurate estimate of resistance to "initial infection" would be by spray inoculation with Tri5-, or even by using grain spawn infected with Tri5-. This would eliminate the interference of type II and III resistances in our evaluation of resistance to initial infection. On the other hand, in addition to the remaining problems or difficulties in quantifying spore exposure and controlling environmental conditions, using Tri5- to test for type I resistance would be accompanied with its own set of constraints. The Tri5- strain is a valuable tool for addressing fundamental research questions, but is not as functional in applied research. Breeders will still need to address the other components of resistance, and while the evaluation of type I resistance is confounded by other forms of resistance, breeders and farmers may be interested in these other forms of resistance-they want cultivars that are resistant to spray inoculation and to all that entails. They want crops that are resistant to the disease, not to components of the disease. While good type I resistance may be the most effective means to 
prevent the disease from occurring, these genotypes are not immune to the disease, and the additional components of resistance will therefore play an important role in crop protection.

Table 2. FHB resistance mechanisms in cereals.

\begin{tabular}{ll}
\hline Resistance & Description \\
\hline Resistance in Small Grain & Cereals (as defined in reference 99) \\
\hline Type I & Resistance to initial infection [90] \\
Type II & Resistance to disease spread [90] \\
Type III & Resistance to kernel infection [87] \\
Type IV & Tolerance against FHB and trichothecenes [87] \\
Type V & Resistance to trichothecene accumulation [97] \\
class 1 & by chemical modification of trichothecenes [83] \\
class 2 & by inhibition of trichothecene synthesis [83] \\
\hline Resistance in Maize & \\
\hline Silk Resistance & Resistance to silk penetration [88] \\
Kernel Resistance & Resistance to kernel disease spread [89] \\
\hline
\end{tabular}

The three remaining forms of resistance (type III, IV, and V) cannot be quantified directly. This is in part, because the nature of these forms of resistance is often intermingled with each other and/or with type I and II resistances. Type III resistance can be assessed by FDK evaluation. Type IV resistance is defined as tolerance to FHB, meaning that yield and quality is maintained despite disease presence. Type IV resistance may also be defined as tolerance to DON, in which case it can be evaluated by comparing FDK values to DON content; if FDK is low but DON content is high, tolerance to DON and FHB would be observed. Type V resistance (resistance to toxin accumulation) can be estimated by DON quantification of FHB-infected plants or by an in vitro tissue assay [97-98]. Type $\mathrm{V}$ resistance can be subdivided into two classes (types V-1 and V-2) as recently defined by Boutigny et al. [83]. In type V-1 resistance, plants are able to chemically modify trichothecenes, resulting in toxin degradation or detoxification. Type V-2 resistance refers to genotypes that have the ability to inhibit trichothecene biosynthesis in the invading fungus.

\subsection{Sources of Resistance}

The development of FHB-resistant cultivars has proven to be a difficult task. While cereal breeders worldwide have invested a considerable effort in the development of FHB-resistant germplasm [9, 12, 99-102], relatively few resistant cultivars have been generated by conventional breeding methods. Moreover, most of the work has focused on wheat and barley breeding. This is a direct result of the FHB-impact on wheat and barley (especially wheat) in comparison to other cereals. Wheat is one of the most heavily FHB-affected crops and accumulates the largest economic damage. Rye is generally more resistant than wheat and barley [5, 100]. Oats are also more resistant than wheat and barley [5], but DON accumulation in oats is more severe than in wheat [103]. T-2 and HT-2 toxin accumulation 
has been observed in oats in Norwegian countries, due to infection with head blight causing $F$. langsethiae [104]. Higher apparent FHB-resistance in oat is, in part, due to difficulties in screening for resistance. Disease symptoms of Fusarium-infected standing oat are not as readily discernable as in wheat or barley where symptoms are clearly visible [102].

Barley has an inherent type II resistance [5], but unconventional disease spread can be observed externally from spikelet to spikelet without penetration of the rachis [5]. Six-row barley, which is more susceptible than two-row barley and is preferred for malting, is nearly as susceptible as wheat [101]. Chevron, the major source of resistance in six-row barley, is not well-liked in the brewing and malting industries due to elevated protein content [105]. QTL for FHB-resistance have been found on all seven barley chromosomes [106-108]. Resistance in two-row barley is attributed to a QTL that is associated with the Vrs1 locus, which controls spike type. It is not clear whether resistance is linked to Vrs1, of if there is a pleiotropic effect at play.

Durum wheat (Triticum turgidum subsp. durum) is one of eight subspecies of tetraploid (AABB) wheat [109], and is far more FHB-susceptible than hexaploid (AABBDD) bread wheat [9]. Breeders have screened for resistant sources in various T. turgidum subspecies. Wild emmer wheat (T. turgidum subsp. dicoccoides) has been the major focus for alternative tetraploid wheat resistance; however, poor agronomic traits have prevented its use in breeding programs. Recently, Oliver et al. took on the task of systematically screening seven $T$. turgidum subspecies, and have identified some with promise as type II resistant sources [109]. Four QTL have been identified for FHB-resistance in tetraploid wheat: 3AS and 7AS from different accessions of T. turgidum subsp. dicoccoides, and 2BS and 6BS from durum wheat [110].

Over 100 QTL have been reported from FHB-resistant wheat sources-22 of which have been found in multiple mapping populations, and are nicely summarized in a recent review by Bürstmayr et al. [110]. The best characterized and most widely used source of resistance in hexaploid wheat is the Chinese cultivar, 'Sumai3' [110-111]. 'Sumai3'-derived resistance is attributed to the Fhb1 locus on chromosome 3BS, the major QTL conferring type II resistance. Positional cloning of Fhb1 is underway, and gene identification may become available within the next year or so [112]. Additional QTL from 'Sumai3' include Fhb2 (6BS) and Qfhs.ifa-5A (5A), the latter being associated with type I resistance and found in different germplasm from around the world [110]. Another popular resistance source comes from the Brazilian cultivar, 'Frontana', with moderate resistance, and QTL mapped to 3A, 5A, 2B, 3AL, and 7AS [110, 113-115]. An interesting set of QTL for FHB-resistance may be associated with Rht plant height regulators. Some studies have shown that plant height is correlated with FHB-resistance [115-117], although rare exceptions may be found (A. Comeau, unpublished data). Rht-D1 co-localizes with FHB-resistant QTL on 4DS, found in the European winter wheat cultivar, Arina [118]. Rht-B1 is on the same chromosome as an FHB-resistant QTL on 4B, and Rht8 is close to a QTL on 2D. Rht-B1 and Rht-D1 are derepressors of gibberellin-signaling, and Rht8 is gibberellin-responsive. The so-called semi-dwarfing alleles, Rht-B1b and Rht-D1b, confer gibberellininsensitivity [119]. Rht-D1b, but not Rht-B1b, also confers FHB-susceptibility [118, 120]. It has not yet been determined whether or not there is a pleiotropic effect at play in this interaction [118].

Research in fusarium ear blight (FEB; FHB of maize)-resistance in maize is less extensive than in wheat and barley, and few resistant cultivars have been generated. Canadian inbred lines with resistance include CO272 [moderate silk resistance; 89], CO325 [moderate kernel resistance; 89] and 
CO441 [with both silk and kernel resistance; 121]. To our knowledge, only two studies have been published in the identification of QTL for FEB-resistant maize [122-123]. Ali et al. identified 11 QTL for silk-resistance and 18 QTL for kernel-resistance, two of which were also associated with silkresistance [122]. Microarray-based comparative genomic hybridization is currently underway to identify genes corresponding to those QTL [124]. It is essential that more research be put into FEBresistance in maize, maize is a major staple food and production has increased in the United States due to the biofuel initiatives. As a result of increased maize production we should expect to see an increase in inoculum build-up in the soil, and maize is one of the worst culprits for harbouring ascospores. By improving maize resistance to FEB, we will not only protect maize crops, but indirectly protect other crops that would be affected by the aforementioned potential increase in inoculum build-up. This is, in fact, an issue of food security. The increase in maize production for non-food products is already taking away valuable farmland for food production, thus reducing the quantity of wheat and barley, among other crops. If the soil-borne inocula were to increase, this would threaten the already dwindling food supply of wheat and other grains. This issue also reiterates the importance of producing highly resistant cultivars of all the other susceptible cereals.

\subsection{Breeding for Resistance}

Some of the challenges breeders are confronted with include: (1) poor agronomic traits associated with highly-resistant germplasm, which are often derived from exotic sources, (2) the polygenic nature of resistance, and (3) variability in disease rating such as those described in section 3.1. Unfortunately, breeders have been limited in their choices of resistant sources, and some of these problems perpetuate themselves. For example, while gene-for-gene resistance is presented with its own set of difficulties [such as the development of an arms-race between host and pathogen; 125], the lack of vertical resistance in FHB-host interactions precludes the prospect of immunity. As a consequence, when breeders find stable, highly-resistant sources, they use this source of resistance-as they should. However, if there are only a handful of these resistant sources available, then they will be used overand-over again, ultimately leading to the arms-race scenario observed in gene-for-gene resistance. Limiting breeding programs to one (or a few) resistant sources can initiate the selection of highly pathogenic strains with the ability to disarm or dilute the resistant strategy of cultivated lines. This limitation brings us back to the original problem: FHB-resistance is quantitative. Therefore, the use of only a limited number of resistant sources in the development of resistant germplasm is not terribly effective. In addition, most of these resistant sources have poor agronomic traits-and so you can see the cycle continuing. 'Sumai3' is the prime example of a stable resistant source that is used in breeding programs around the world. The stability and level of resistance is higher than in any other registered cultivar. Other popular resistant sources exist (ex. 'Frontana'), but there are only a few of them. In addition, 'Sumai3' is blighted with several agronomic fallacies, including susceptibility to kernel shattering and reduced yields [126].

In the past few decades, several tactics have emerged in an effort to enhance, or as an alternative to, traditional breeding methods. Traditional breeding is a long and tedious process, requiring many generations of screening, which can be costly and time consuming. Breeders often screen thousands of lines, narrowing them down every year, for up to ten years, before one or two lines are ready for the 
application process to register a cultivar. Screening for FHB-severity alone is time consuming, but screening for trichothecene accumulation (which is a necessary step) is both time-consuming and costly. Several studies have shown that percent FDK serves as a reliable estimate of DON content [33, 127]. For this reason, and because it is rapid and inexpensive, FDK is frequently used to screen for resistance to DON accumulation in breeding programs. Since FHB-severity is highly correlated with seed quality and DON content (127), it is recommended that breeders screen only for FHB-severity in the early years, and then use DON quantification when the number of breeding lines has been narrowed down [31].

The use of QTL (such as those described in section 3.2) as molecular markers for resistance can facilitate breeding in the early stages of screening, and can effectively attenuate some of the error in the disease rating variability. Other methods have been proposed to decrease the occurrence of these errors in rating disease, in particular indoor spray inoculation which mimics natural infection [128]. The indoor spray inoculation method using a mist-irrigated greenhouse allows for a relatively rapid screening of advanced material, as well as screening of earlier $\mathrm{F}_{2-4}$ generations and doubled haploid genotypes. Indoor spray inoculation also offers the possibility of running phenotypic evaluations throughout the calendar year, which is not possible in a nursery, and is more likely to prevent competing organisms (e.g., Bipolaris sorokiniana (Sacc.) Shoemaker) from confounding the evaluations.

The idea of using trichothecenes as factors for early selection of resistant cereal lines, or reduced accumulation of mycotoxins, is very attractive. Large cell samples can be evaluated in Petri dishes, where environmental conditions are uniform. Bruins et al. suggested that single-cell microspores might be better suited for in vitro selection since a large proportion of the plant genome is expressed in both the sporophyte and the gametophyte [129]. Fadel and Wenzel were the first to report a mixed culture filtrate of 99 F. graminearum isolates co-cultured in 10-day old anther cultures [130]. However, they did not report successful selection for resistance among regenerated plants. In a similar study, Eudes et al. also co-cultured crude trichothecenes in an anther culture assay to report effective selection for reduced mycotoxin accumulation when using the more defined selection agent [131]. This in vitro selection process was successful using source of resistance Frontana, and was genotype dependant.

\subsection{Engineering for Resistance}

Several reviews have been published on the advantages of genetic engineering toward improvement of crop resistance to various pathogens, including FHB [132-134]. Genetic engineering towards FHBresistance can be effective in reducing mycotoxin accumulation in cereals. Transgenic crops can directly reduce trichothecene accumulation when the modifications include expression of genes or pathways within the host that inhibit trichothecene synthesis, detoxify trichothecenes, or remove them from the cell by efflux. Boutigny et al. recently published a review summarizing the known methods naturally expressed by plants to reduce trichothecene accumulation [83]. Examples of enzymes that may be involved in detoxification include epoxidases, acetyltransferases, and glycosyltransferases [83]. While there is no evidence of de-epoxidation in planta [83], the epoxide group has been shown to be essential for trichothecene toxicity [135]. Trichothecene 3-O-acetyltransferase activity of TRI101, which leads to DON-acetylation, has been shown to reduce toxicity of trichothecenes in $F$. 
graminearum [136]. It has also been demonstrated that 3-ADON is less cytotoxic than DON [137]. Transgenic expression of TRI101 in plants has shown improved FHB- and trichothecene-resistance [138-140]. Another Fusarium gene, Tri12, is a major facilitator superfamily (MFS) transporter responsible for trichothecene efflux from $F$. sporotrichioides [141], also has the potential to reduce trichothecene accumulation in plants.

UDP-glucosyltransferase has been shown to detoxify DON, by condensation of a glucose molecule on the hydroxyl group at C-3 [142], and glycosylated-DON derivatives have been observed in Fusarium-infected cereals [143-145]. It has been hypothesized that Fhb1 of 'Sumai3' is in fact a UDPglucosyltransferase [145]. Fine-mapping of Fhb1 by James Anderson's research group in Minnesota have narrowed it down to a few candidate genes. Surprisingly, none of these encode UDPglucosyltransferase, but this does not eliminate the possibility that Fhb1 is involved in the regulation of UDP-glucosyltransferase expression [112]. Differential accumulation of UDP-glucosyltransferase transcript and protein has been observed in wheat (Foroud et al., in preparation) and maize (Harris et al., in preparation), respectively. Transgenic expression of UDP-glucosyltransferase might lead to improved FHB-resistance and reduced toxin accumulation; however, this approach may be dangerously misleading. Studies have shown than glycosylated-ZON can be reconverted to ZON in the intestinal tract of swine [146].

\section{Conclusions}

Trichothecene contamination of cereals represents a threat to the economies and food supplies of cereal growing regions around the world. More importantly, in countries where there is limited or no screening for trichothecene contamination, it represents a significant health threat. We would like to make three recommendations to breeders and scientists to help reduce the threat of trichotheceneinduced damages. The first of these is already a goal most breeders strive towards, and that is to breed for highly-resistant cultivars with good agronomic traits. Highly-resistant cultivars express stable resistance under epidemic conditions, moderate FHB-resistance is not good enough. Highly-resistant cultivars are of little use if farmers choose not to grown them, and so good agronomics in combination with resistance is essential.

Our second recommendation is one recently made by Boutigny et al., and that is to breed for type $\mathrm{V}$ resistance [83]. While trichothecene screening is costly and time consuming in breeding programs, resistance to DON-accumulation is of utmost importance. Most other forms of resistance may be improved in the presence of type $\mathrm{V}$ resistance, and type $\mathrm{V}$ resistance may be a consequence of other forms of resistance; however, all other forms of resistance are irrelevant if trichothecenes accumulate in the grain. Moreover, breeding for type V-2 (by inhibition of trichothecene biosynthesis) is preferred over type V-1 (chemical modification of trichothecenes), since it is unclear whether the modified trichothecenes remain detoxified upon ingestion. While distinguishing between the two classes of type $\mathrm{V}$ resistance may present more time and cost to breeders, these inconveniences can be reduced following recommendations by Miedaner et al. [31]. That is to screen first for FHB-severity, and once the breeding lines have been narrowed down screen for resistance to trichothecene accumulation. DON quantification by ELISA is much more affordable than GC-MS or LC-MS/MS, but the advantage of mass spectrophotometry-based techniques is that multiple trichothecenes can be detected, and 
glycosylated derivatives can also be detected [147-153]. In vitro selection is a very effective method to select for good resistance to trichothecenes, though sources of resistance have to be adequately identified. As well, these early screening methods should be used in combination with disease rating in controlled environments and could be applied with molecular marker assisted selection for the major QTLs.

Finally, our third recommendation to reduce the impact of trichothecene contamination in the foodsupply is to breed for resistance in "other crops" - that is to say in addition to wheat and barley. Most breeding efforts/successes have been reported in wheat and barley, especially wheat, but there are many other crops (such as maize, oats, rye and triticale) which are affected by FHB and accumulate trichothecenes that do not get as much attention as they may deserve. Breeding for resistance to FEB in maize is of particular importance, since maize crop residue is known to be a major source of soilborne inoculum. The presence of type A trichothecenes (which are not usually screened for in food products) in oat and oat products as a result of infection with F. langsethiae [104, 173] emphasizes the need to breed more resistant oats-even though this crop is not typically seen as highly susceptible in comparison to wheat, barley and corn. Disease in these crops leads not only to contamination in the food chain, but also to inoculum build-up in the soil, which subsequently leads to increased epidemics and increased risk of trichothecene contamination within our food supply. The development and the farming of highly resistant cultivars (resistant to the disease and to trichothecene accumulation), in all cereal crops affected by this disease, will go a long way in protecting the consumer from health hazards associated with ingestion of trichothecene-contaminated grain, and in protecting farmers from the economic impacts of this disease.

\section{Acknowledgements}

We would like to thank Drs. André Comeau (Agriculture and Agri-Food Canada; AAFC), Hermann Bürstmayr (University of Natural Resources and Applied Life Sciences Vienna), Linda Harris (AAFC), Randall Clear (Canadian Grain Commission; CRC), Robert Proctor (United States Department of Agriculture) and Tom Nowicki (CRC), for their personal communications, and Dr. Paul Hayes (University of Lethbridge) for his revisions.

\section{References and Notes}

1. Parry, D.W.; Jenkinson, P.; McLeod, L. Fusarium ear blight (scab) in small grain cereals-a review. Plant Pathol. 1995, 44, 207-238.

2. Tóth, B.; Mesterházy, Á.; Horvath, Z.; Bartók, T.; Varga, M.; Varga, J. Genetic Variability of Central European Isolates of the Fusarium graminearum Species Complex. Eur. J. Plant Pathol. 2005, 113, 35-45.

3. Eudes, F.; Comeau, A.; Rioux, S.; Collin, J. Impact of trichothecenes on fusarium head blight (Fusarium graminearum) development in spring wheat (Triticum aestivum). Can. J. Plant Pathol. 2001, 23, 318-322.

4. Harris, L.J.; Desjardins, A.E.; Plattner, R.D.; Nicholson, P.; Butler, G.; Young, Y.C.; Weston, G.; Proctor, R.H.; Hohn, T.M. Possible role of trichothecene mycotoxins in virulence of Fusarium graminearum on maize. Plant Dis. 1999, 83, 954-960. 
5. Langevin, F.; Eudes, F.; Comeau, A. Effect of trichothecenes produced by Fusarium graminearum during fusarium head blight development in six cereal species. Eur. J. Plant Pathol. 2004, 110, 735-746.

6. Proctor, R.H.; Hohn, T.M.; McCormick, S.P. Reduced virulence of Gibberella zeae caused by disruption of a trichothecene toxin biosynthetic gene. Mol. Plant-Microbe Interact. 1995, 8, 593-601.

7. Eriksen, G.S.; Pettersson, H. Toxicological evaluation of trichothecenes in animal feed. Anim. Feed Sci. Technol. 2004, 114, 205-239.

8. Stack, R.W. History of fusarium head blight with emphasis on North America. In Fusarium Head Blight of Wheat and Barley; Leonard, K.J., Bushnell, W.R., Eds.; The American Phytopathological Society: St. Paul, Minnesota, USA, 2003; Chapter 1, pp. 1-34.

9. Gilbert, J.; Tekauz, A. Review: Recent developments in research on fusarium head blight of wheat in Canada. Can. J. Plant Pathol. 2000, 22, 1-8.

10. Moschini, R.C.; Fortugno, C. Predicting wheat head blight incidence using models based on meteorological factors in Pergamino, Argentina. Eur. J. Plant Pathol. 1996, 102, 211-218.

11. McMullen, M. Impacts of fusarium head blight on North American agricultural community: The power of one disease to catapult change. In Fusarium Head Blight of Wheat and Barley; Leonard, K.J., Bushnell, W.R., Eds.; The American Phytopathological Society: St. Paul, Minnesota, USA, 2003; Chapter 18, pp. 484-503.

12. Bai, G.-H.; Chen, L.-F.; Shaner, G.E. Breeding for resistance to fusarium head blight of wheat in China. In Fusarium Head Blight of Wheat and Barley; Leonard, K.J., Bushnell, W.R., Eds.; The American Phytopathological Society: St. Paul, Minnesota, USA, 2003; Chapter 11, pp. 296-317.

13. Bhat, R.V.; Beedu, S.R.; Ramakrishna, Y.; Munshi, K.L. Outbreak of Trichothecene mycotoxicosis associated with consumption of mold-damaged wheat products in Kashmir Valley India. Lancet 1989, 1, 35-37.

14. Burgess, L.W.; Klein, T.A.; Bryden, W.L.; Tobin, N.F. Head Blight of Wheat Caused by Fusarium graminearum Group 1 in New South Wales Australia in 1983. Australas. Plant Pathol. 1987, 16, 72-78.

15. Xu, X.M.; Nicholson, P.; Thomsett, M.A.; Simpson, D.; Cooke, B.M.; Doohan, F.M.; Brennan, J.; Monaghan, S.; Moretti, A.; Mule, G.; Homok, L.; Beki, E.; Tatnell, J.; Ritieni, A.; Edwards, S.G. Relationship between the fungal complex causing fusarium head blight of wheat and environmental conditions. Phytopathology 2008, 98, 69-78.

16. Kriel, W.M.; Pretorius, Z.A. The FHB challenge to irrigation wheat production in South Africa. Cereal Res. Commun. 2008, 36, 569-571.

17. Scott, D.B.; De Jager, E.J.H.; Van Wyk, P.S. Head blight of irrigated wheat in South Africa. Phytophylactica 1988, 20, 317-319.

18. McMullen, M.; Jones, R.; Gallenberg, D. Scab of wheat and barley: A re-emerging disease of devasting impact. Plant Dis. 1997, 81, 1340-1348.

19. Xu, X. Effects of environmental conditions on the development of Fusarium ear blight. Eur. $J$. Plant Pathol. 2003, 109, 683-689.

20. Hongxiang, M.; Yao, J.; Zhou, M.; Zhang, X.; Ren, L.; Yu, G.; Lu, W. Molecular breeding for wheat fusarium head blight resistance in China. Cereal Res. Commun. 2008, 36, 1-730. 
21. Dill-Macky, R.; Jones, R.K. The effect of previous crop residues and tillage on fusarium head blight of wheat. Plant Dis. 2000, 84, 71-76.

22. Gilbert, J.; Fernando, W.G.D. Epidemiology and biological control of Gibberella zeae Fusarium graminearum. Can. J. Plant Pathol. 2004, 26, 464-472.

23. Horsley, R.D.; Pederson, J.D.; Schwarz, P.B.; McKay, K.; Hochhalter, M.R.; McMullen, M.P. Integrated use of tebuconazole and fusarium head blight-resistant barley genotypes. Agron. J. 2006, 98, 194-197.

24. Jones, R.K. Assessments of fusarium head blight of wheat and barley in response to fungicide treatment. Plant Dis. 2000, 84, 1021-1030.

25. Khan, M.R.; Fischer, S.; Egan, D.; Doohan, F.M. Biological control of Fusarium seedling blight disease of wheat and barley. Phytopathology 2006, 96, 386-394.

26. Miller, J.D.; Culley, J.; Fraser, K.; Hubbard, S.; Meloche, F.; Ouellet, T.; Seaman, W.L.; Seifert, K.A.; Turkington, K.; Voldeng, H. Effect of tillage practice on fusarium head blight of wheat. Can. J. Plant Pathol. 1998, 20, 95-103.

27. Paul, P.A.; Lipps, P.E.; Hershman, D.E.; McMullen, M.P.; Draper, M.A.; Madden, L.V. A Quantitative review of tebuconazole effect on fusarium head blight and deoxynivalenol content in wheat. Phytopathology 2007, 97, 211-220.

28. De Wolf, E.D.; Madden, L.V.; Lipps, P.E. Risk assessment models for wheat fusarium head blight epidemics based on within-season weather data. Phytopathology 2003, 93, 428-435.

29. Prandini, A.; Sigolo, S.; Filippi, L.; Battilani, P.; Piva, G. Review of predictive models for fusarium head blight and related mycotoxin contamination in wheat. Food Chem. Toxicol. 2008, [epub].

30. McMullen, M.; Halley, S.; Schatz, B.; Meyer, S.; Jordahl, J.; Ransom, J. Integrated strategies for fusarium head blight management in the United States. Cereal Res. Commun. 2008, 36, 563-568.

31. Miedaner, T.; Reinbrecht, C.; Lauber, U.; Schollenberger, M.; Geiger, H.H. Effects of genotype and genotype-environment interaction on deoxynivalenol accumulation and resistance to fusarium head blight in rye, triticale, and wheat. Plant Breed. 2001, 120, 97-105.

32. Foroud, N.; MacMillan, T.; Ellis, B.; Eudes, F. The role of trichothecene-chemotypes in fusarium head blight disease spread in wheat. Cereal Res. Commun. 2008, 36, 489-490.

33. Mesterházy, Á. Role of deoxynivalenol in aggressiveness of Fusarium graminearum and F. culmorum and in resistance to fusarium head blight. Eur. J. Plant Pathol. 2002, 108, 675-684.

34. Desjardins, A.E.; Hohn, T.M.; McCormick, S.P. Trichothecene biosynthesis in Fusarium species: Chemistry, genetics, and significance. Microbiol. Rev. 1993, 57, 595-604.

35. Mirocha, C.J.; Xie, W.; Filho, E.R. Chemistry and detection of Fusarium mycotoxins. In Fusarium Head Blight of Wheat and Barley; Leonard, K.J., Bushnell, W.R., Eds.; The American Phytopathological Society: St. Paul, Minnesota, USA, 2003; Chapter 6, pp. 144-164.

36. Liddell, C.M. Systematics of Fusarium species and allies associated with fusarium head blight. In Fusarium Head Blight of Wheat and Barley; Leonard, K.J., Bushnell, W.R., Eds.; The American Phytopathological Society: St. Paul, Minnesota, USA, 2003; Chapter 2, pp. 35-43.

37. Ueno, Y. Trichothecenes: Chemical, Biological and Toxicological Aspects. Elsevier Scientific Publishers: Amsterdam, 1983. 
38. Sudakin, D.L. Trichothecenes in the environment: Relevance to human health. Toxicol. Lett. 2003, 143, 97-107.

39. Desjardins, A.E.; Proctor, R.H. Molecular biology of Fusarium mycotoxins. Int. J. Food Microbiol. 2007, 119, 47-50.

40. Harris, L.J.; Alexander, N.J.; Saparno, A.; Blackwell, B.; McCormick, S.P.; Desjardins, A.E.; Robert, L.S.; Tinker, N.; Hattori, J.; Piche, C.; Schernthaner, J.P.; Watson, R.; Ouellet, T. A novel gene cluster in Fusarium graminearum contains a gene that contributes to butenolide synthesis. Fungal Genet. Biol. 2007, 44, 293-306.

41. Hohn, T.M.; Vanmiddlesworth, F. Purification and characterization of the sesquiterpene cyclase trichodiene synthetase from Fusarium sporotrichioides. Arch. Biochem. Biophys. 1986, 251, 756-761.

42. Hohn, T.M.; Desjardins, A.E.; McCormick, S.P. The Tri4 gene of Fusarium sporotrichioides encodes a cytochrome P450 monooxygenase involved in trichothecene biosynthesis. Mol. Gen. Genet. 1995, 248, 95-102.

43. McCormick, S.P.; Alexander, N.J.; Proctor, R.H. Fusarium Tri4 encodes a multifunctional oxygenase required for trichothecene biosynthesis. Can. J. Microbiol. 2006, 52, 636-642.

44. McCormick, S.P.; Taylor, S.L.; Plattner, R.D.; Beremand, M.N. Bioconversion of possible T-2 toxin precursors by a mutant strain of Fusarium sporotrichioides NRRL 3299. Appl. Environ. Microbiol. 1990, 56, 702-6.

45. McCormick, S.P.; Alexander, N.J.; Trapp, S.E.; Hohn, T.M. Disruption of TRI101, the gene encoding trichothecene 3-O-acetyltransferase, from Fusarium sporotrichioides. Appl. Environ. Microbiol. 1999, 65, 5252-5256.

46. Alexander, N.J.; Hohn, T.M.; McCormick, S.P. The TRI11 gene of Fusarium sporotrichioides encodes a cytochrome P-450 monooxygenase required for C-15 hydroxylation in trichothecene biosynthesis. Appl. Environ. Microbiol. 1998, 64, 221-225.

47. McCormick, S.P.; Hohn, T.M.; Desjardins, A.E. Isolation and characterization of Tri3, a gene encoding 15-O-acetyltransferase from Fusarium sporotrichioides. Appl. Environ. Microbiol. 1996, 62, 353-9.

48. Desjardins, A.E. Natural product chemistry meets genetics: when is a genotype a chemotype? $J$. Agric. Food Chem. 2008, 56, 7587-7592.

49. Lee, T.; Han, Y.K.; Kim, K.H.; Yun, S.H.; Lee, Y.W. Tri13 and Tri7 determine deoxynivalenoland nivalenol-producing chemotypes of Gibberella zeae. Appl. Environ. Microbiol. 2002, 68, 2148-2154.

50. Brown, D.W.; McCormick, S.P.; Alexander, N.J.; Proctor, R.H.; Desjardins, A.E. A genetic and biochemical approach to study trichothecene diversity in Fusarium sporotrichioides and Fusarium graminearum. Fungal Genet. Biol. 2001, 32, 121-133.

51. Rocha, O.; Ansari, K.; Doohan, F.M. Effects of trichothecene mycotoxins on eukaryotic cells: A review. Food Addit. Contam. 2005, 22, 369-378.

52. McLaughlin, C.S.; Vaughn, M.H.; Campbell, J.M.; Wei, C.M.; Stafford, M.E. Mycotoxins in Human and Health; Rodricks, J.V., Hesseltine, C.W., Mehlman, M.A., Eds.; Pathotox Publishers: Park Forest South, Illinois, 1977; pp. 263-275.

53. Ueno, Y. Mode of action of trichothecenes. Ann. Nutr. Aliment. 1977, 31, 885-900. 
54. Ueno, Y. The toxicology of mycotoxins. Crit. Rev. Toxicol. 1985, 14, 99-133.

55. Minervini, F.; Fornelli, F.; Flynn, K.M. Toxicity and apoptosis induced by the mycotoxins nivalenol, deoxynivalenol and fumonisin B1 in a human erythroleukemia cell line. Toxicol. In Vitro 2004, 18, 21-28.

56. Thompson, W.L.; Wannemacher, R.W.J. Structure-function relationships of 12,13epoxytrichothecene mycotoxins in cell culture comparison to whole animal lethality. Toxicon 1986, 24, 985-994.

57. Pace, J.G.; Watts, M.R.; Canterbury, W.J. T-2 Mycotoxin inhibits mitochondrial protein synthesis. Toxicon 1988, 26, 77-86.

58. Bunner, D.L.; Morris, E.R. Alteration of multiple cell Membrane functions in L-6 myoblasts by T-2 toxin an important mechanism of action. Toxicol. Appl. Pharmacol. 1988, 92, 113-121.

59. Kang, Z.; Buchenauer, H. Immunocytochemical localization of Fusarium toxins in infected wheat spikes by Fusarium culmorum. Physiol. Mol. Plant Pathol. 1999, 55, 275-288.

60. Islam, Z.; Pestka, J.J. Role of IL-1beta in endotoxin potentiation of deoxynivalenol-induced corticosterone response and leukocyte apoptosis in mice. Toxicol. Sci. 2003, 74, 93-102.

61. Shifrin, V.I.; Anderson, P. Trichothecene mycotoxins trigger a ribotoxic stress response that activates c-Jun N-terminal kinase and p38 mitogen-activated protein kinase and induces apoptosis. J. Biol. Chem. 1999, 274, 13985-13992.

62. Yoshino, N.; Takizawa, M.; Tashiro, F.; Honda, M.; Ueno, Y. T-2 toxin induced apoptosis in human peripheral blood lymphocytes in vitro. Res. Commun. Biochem. Cell Mol. Biol. 1997, 1, 218-228.

63. Mayer, C.F. Endemic panmyelotoxicosis in the Russian grain belt. I. The clinical aspects of alimentary toxic aleukia (ATA); a comprehensive review. Mil. Surg. 1953, 113, 173-189.

64. Yagen, B.; Joffe, A.Z. Screening of toxic isolates of Fusarium poae and Fusarium sporotrichioides involved in causing alimentary toxic aleukia. Appl. Environ. Microbiol. 1976, 32, 423-427.

65. Del, P.E.M.; Fernandes, J.M.C.; Bergstrom, G.C. Influence of growth stage on fusarium head blight and deoxynivalenol production in wheat. J. Phytopathol. 2007, 155, 577-581.

66. Bushnell, W.R.; Hazen, B.E.; Pritsch, C. Histology and physiology of fusarium head blight. In Fusarium Head Blight of Wheat and Barley; Leonard, K.J., Bushnell, W.R., Eds.; The American Phytopathological Society: St. Paul, Minnesota, USA, 2003; Chapter 3, pp. 44-83.

67. Steffenson, B.J. Fusarium head blight of barley: Impact, epidemics, management, and strategies for identifying and utilizing genetic resistance. In Fusarium Head Blight of Wheat and Barley; Leonard, K.J., Bushnell, W.R., Eds.; The American Phytopathological Society: St. Paul, Minnesota, USA, 2003; Chapter 10, pp. 241-295.

68. Hart, L.P.; Pestka, J.J.; Liu, M.T. Effect of kernel development and wet periods on production of deoxynivalenol in wheat infected with Gibberella zeae. Phytopathology 1984, 74, 1415-1418.

69. Pestka, J.J.; Smolinski, A.T. Deoxynivalenol: Toxicology and potential effects on humans. $J$. Toxicol. Environ. Health B Crit. Rev. 2005, 8, 36-39.

70. Rotter, B.A.; Prelusky, D.B.; Pestka, J.J. Toxicology of deoxynivalenol (Vomitoxin). J. Toxicol. Environ. Health 1996, 48, 1-34. 
71. Wolpert, T.J.; Dunkle, L.D.; Ciuffetti, L.M. Host-selective toxins and avirulence determinants: What's in a name? Annu. Rev. Phytopathol. 2002, 40, 251-85.

72. Tanaka, A.; Shiotani, H.; Yamamoto, M.; Tsuge, T. Insertional mutagenesis and cloning of the genes required for biosynthesis of the host-specific AK-toxin in the Japanese pear pathotype of Alternaria alternata. Mol. Plant-Microbe Interact. 1999, 12, 691-702.

73. Navarre, D.A.; Wolpert, T.J. Victorin induction of an apoptotic/senescence-like response in oats. Plant Cell 1999, 11, 237-249.

74. Baker, S.E.; Kroken, S.; Inderbitzin, P.; Asvarak, T.; Li, B.Y.; Shi, L.; Yoder, O.C.; Turgeon, B.G. Two polyketide synthase-encoding genes are required for biosynthesis of the polyketide virulence factor, T-toxin, by Cochliobolus heterostrophus. Mol. Plant-Microbe Interact. 2006, 19, 139-149.

75. Reino, J.L.; Hernandez, G.R.; Duran, P.R.; Collado, I.G. Virulence-toxin production relationship in isolates of the plant pathogenic fungus Botrytis cinerea. J. Phytopathol. 2004, 152, 563-566.

76. Cotty, P.J.; Misaghi, I.J. Zinniol Production by Alternaria Species. Phytopathology 1984, 74, 785-788.

77. Beremand, M.N.; Desjardins, A.E.; Hohn, T.M.; Vanmiddlesworth, F.L. Survey of Fusarium sambucinum Equals Gibberella pulicaris for Mating Type Trichothecene production and other selected tTraits. Phytopathology 1991, 81, 1452-1458.

78. Miedaner, T.; Reinbrecht, C.; Schilling, A.G. Association among aggressiveness, fungal colonization, and mycotoxin production of 26 isolates of Fusarium graminearum in winter rye head blight. Z. Pflanzenkr. Pflanzenschutz 2000, 107, 124-134.

79. Perkowski, J.; Kiecana, I.; Schumacher, U.; Mueller, H.M.; Chelkowski, J.; Golinski, P. Head blight and biosynthesis of Fusarium toxins in barley kernels field inoculated with Fusarium culmorum. Eur. J. Plant Pathol. 1996, 102, 491-496.

80. Snijders, C.H.A.; Perkowski, J. Effects of head blight caused by Fusarium culmorum on toxin content and weight of wheat kernels. Phytopathology 1990, 80, 570.

81. Mesterházy, Á.; Bartók, T.; Mirocha, C.G.; Komoroczy, R. Nature of wheat resistance to fusarium head blight and the role of deoxynivalenol for breeding. Plant Breed. 1999, 118, 97-110.

82. Arseniuk, E.; Góral, T.; Czembor, H.J. Reaction of triticale, wheat and rye accessions to graminaceous Fusarium spp. infection at the seedling and adult plant growth stages. Euphytica 1993, 70, 175-183.

83. Boutigny, A.L.; Richard, F.F.; Barreau, C. Natural mechanisms for cereal resistance to the accumulation of Fusarium trichothecenes. Eur. J. Plant Pathol. 2008, 121, 411-423.

84. Bai, G.-H.; Desjardins, A.E.; Plattner, R.D. Deoxynivalenol-nonproducing Fusarium graminearum causes initial infection, but does not cause disease spread in wheat spikes. Mycopathologia 2002, 153, 91-8.

85. Maier, F.J.; Miedaner, T.; Hadeler, B.; Felk, A.; Salomon, S.; Lemmens, M.; Kassner, H.; Schaefer, W. Involvement of trichothecenes in fusarioses of wheat, barley and maize evaluated by gene disruption of the trichodiene synthase (Tri5) gene in three field isolates of different chemotype and virulence. Mol. Plant Pathol. 2006, 7, 449-461. 
86. Jansen, C.; von, W.D.; Schaefer, W.; Kogel, K.H.; Felk, A.; Maier, F.J. Infection patterns in barley and wheat spikes inoculated with wild-type and trichodiene synthase gene disrupted Fusarium graminearum. Proc. Natl. Acad. Sci. USA 2005, 102, 16892-16897.

87. Mesterházy, Á. Types and components of resistance to fusarium head blight of wheat. Plant Breed. 1995, 114, 377-386.

88. Reid, L.M.; Mather, D.E.; Hamilton, R.I.; Bolton, A.T. Genotypic differences in the resistance of maize silk to Fusarium graminearum. Can. J. Plant Pathol. 1992, 14, 211-214.

89. Chungu, C.; Mather, D.E.; Reid, L.M.; Hamilton, R.I. Inheritance of kernel resistance to Fusarium graminearum in maize. J. Hered. 1996, 87, 382-385.

90. Schroeder, H.W.; Christensen, J.J. Factors affecting resistance of wheat to scab by Gibberella zeae. Phytopathology 1963, 42, 720-727.

91. Dill-Macky, R. Inoculation methods and evaluation of fusarium head blight resistance in wheat. In Fusarium Head Blight of Wheat and Barley; Leonard, K.J., Bushnell, W.R., Eds.; The American Phytopathological Society: St. Paul, Minnesota, USA, 2003; Chapter 8, pp. 184-210.

92. Rudd, J.C.; Horsley, R.D.; McKendry, A.L.; Elias, E.M. Host plant resistance genes for fusarium head blight: sources, mechanisms, and utility in conventional breeding systems. Crop Sci. 2001, 41, 620-627.

93. Eudes, F.; Zhou, W.; Badea, A.; Laroche, A. Toward the development of fusarium head blight resistance and reduced levels of mycotoxin in wheat and barley. Recent Res. Devel. Plant Pathology 2004, 3, 1-33.

94. Mesterházy, Á.; Tóth, B.; Bartók, T.; Varga, M. Breeding strategies against FHB in winter wheat and their relation to type I resistance Cereal Res. Commun. 2008, 36, 37-43.

95. Kang, Z.; Buchenauer, H. Ultrastructural immunocytochemical investigation of pathogen development and host responses in resistant and susceptible wheat spikes infected by Fusarium culmorum. Physiol. Mol. Plant Pathol. 2000, 57, 255-268.

96. Ilgen, P.; Maier, F.J.; Schäfer, W. Trichothecenes and lipases are host-induced and secreted virulence factors of Fusarium graminearum. Cereal Res. Commun. 2008, 36, 421-428.

97. Miller, J.D.; Young, J.C.; Sampson, D.R. Deoxynivalenol and fusarium head blight resistance in spring cereals. J. Phytopathol. 1985, 113, 359-367.

98. Wang, Y.Z.; Miller, J.D. Effects of Fusarium graminearum metabolites on wheat tissue in relation to fusarium head blight resistance. J. Phytopathol. 1988, 122, 118-125.

99. Mesterházy, Á. Breeding wheat for fusarium head blight resistance in Europe. In Fusarium Head Blight of Wheat and Barley; Leonard, K.J., Bushnell, W.R., Eds.; The American Phytopathological Society: St. Paul, Minnesota, USA, 2003; Chapter 13, pp. 363-381.

100. Miedaner, T. Breeding wheat and rye for resistance to Fusarium diseases. Plant Breed. 1997, 116, 201-220.

101. Tekauz, A.; McCallum, B.; Gilbert, J. Review: Fusarium head blight of barley in western Canada. Can. J. Plant Pathol. 2000, 22, 9-16.

102. Tekauz, A.; McCallum, B.; Ames, N.; Fetch, J.M. Fusarium head blight of oat—current status in western Canada. Can. J. Plant Pathol. 2004, 26, 473-479. 
103. Tekauz, A.; Mitchell Fetch, J.W.; Rossnagel, B.G.; Savard, M.E. Progress in assessing the impact of fusarium head blight on oat in western Canada and screening of avena germplasm for resistance Cereal Res. Commun. 2008, 36, 49-56.

104. Bjørnstad, Å.; Skinnes, H. Resistance to Fusrium infection in oats ( Avena sativa L.) Cereal Res. Commun. 2008, 36, 57-62.

105. Cooper, B.; Skoglund, L.; Askelson, S.; Van Horn, J. In 2nd International Symposium on Fusarium Head Blight: Orlando, FL, USA, 2004; pp. 44-48.

106. de la Pena, R.C.; Smith, K.P.; Capettini, F.; Muehlbauer, G.J.; Gallo, M.M.; Dill, M.R.; Somers, D.A.; Rasmusson, D.C. Quantitative trait loci associated with resistance to fusarium head blight and kernel discoloration in barley. Theor. Appl. Genet. 1999, 99, 561-569.

107. Ma, Z.; Steffenson, B.J.; Prom, L.K.; Lapitan, N.L. Mapping of Quantitative Trait Loci for Fusarium Head Blight Resistance in Barley. Phytopathology 2000, 90, 1079-1088.

108. Zhu, H.; Gilchrist, L.; Hayes, P.; Kleinhofs, A.; Kudrna, D.; Liu, Z.; Prom, L.; Steffenson, B.; Toojinda, T.; Vivar, H. Does function follow form? Principal QTLs for fusarium head blight (FHB) resistance are coincident with QTLs for inflorescence traits and plant height in a doubledhaploid population of barley. Theor. Appl. Genet. 1999, 99, 1221-1232.

109. Oliver, R.E.; Cal, X.; Friesen, T.L.; Halley, S.; Stack, R.W.; Xu, S.S. Evaluation of fusarium head blight resistance in tetraploid wheat (Triticum turgidum L.). Crop Sci. 2008, 48, 213-222.

110. Bürstmayr, H.; Ban, T.; Anderson, A.J. QTL mapping and marker-assisted selection for fusarium head blight resistance in wheat: A review. Plant Breed. 2008, In press.

111. Anderson, J.A. Marker-assisted selection for fusarium head blight resistance in wheat. Int. J. Food Microbiol. 2007, 119, 51-53.

112. Liu, S.; Pumphrey, M.O.; Gill, B.S.; Trick, H.N.; Zhang, J.X.; Dolezel, J.; Chalhoub, B.; Anderson, J.A. Toward positional cloning of Fhb1, a major QTL for fusarium head blight resistance in wheat Cereal Res. Commun. 2008, 36, 195-201.

113. Han, F.P.; Fedak, G.; Ouellet, T.; Dan, H.; Somers, D.J. Mapping of genes expressed in Fusarium graminearum-infected heads of wheat cultivar 'Frontana'. Genome 2005, 48, 88-96.

114. Mardi, M.; Pazouki, L.; Delavar, H.; Kazemi, M.B.; Ghareyazie, B.; Steiner, B.; Nolz, R.; Lemmens, M.; Buerstmayr, H. QTL analysis of resistance to fusarium head blight in wheat using a 'Frontana'-derived population. Plant Breed. 2006, 125, 313-317.

115. Steiner, B.; Lemmens, M.; Griesser, M.; Scholz, U.; Schondelmaier, J.; Bürstmayr, H. Molecular mapping of resistance to fusarium head blight in the spring wheat cultivar Frontana. Theor. Appl. Genet. 2004, 109, 215-24.

116. Couture, L. Susceptibility of spring cereal cultivars to seed contamination by Fusarium-Spp during inflorescence. Can. J. Plant Sci. 1982, 62, 29-34.

117. Klahr, A.; Zimmermann, G.; Wenzel, G.; Mohler, V. Effects of environment disease progress, plant height and heading date on the detection of QTLs or resistance to fusarium head blight in an European winter wheat cross. Euphytica 2007, 154, 17-28.

118. Draeger, R.; Gosman, N.; Steed, A.; Chandler, E.; Thomsett, M.; Srinivasachary; Schondelmaier, J.; Bürstmayr, H.; Lemmens, M.; Schmolke, M.; Mesterházy, Á.; Nicholson, P. Identification of QTLs for resistance to fusarium head blight, DON accumulation and associated traits in the winter wheat variety Arina. Theor. Appl. Genet. 2007, 115, 617-25. 
119. Zhang, X.; Yang, S.; Zhou, Y.; He, Z.; Xia, X. Distribution of the Rht-B1b, Rht-D1b and Rht8 reduced height genes in autumn-sown Chinese wheats detected by molecular markers. Euphytica 2006, 152, 109-116.

120. Nicholson, P.; Sriniv Asachary, N.; Gosman, N.; Steed, A.; Chen, X. Role of phytohormone signalling in resistance of wheat to fusarium head blight Cereal Res. Commun. 2008, 36, 213216.

121. Reid, L.M.; McDiarmid, G.; Parker, A.J.; Woldemariam, T. CO441 corn inbred line. Can. J. Plant Sci. 2003, 83, 79-80.

122. Ali, M.L.; Taylor, J.H.; Jie, L.; Sun, G.; William, M.; Kasha, K.J.; Reid, L. M.; Pauls, K.P. Molecular mapping of QTLs for resistance to Gibberella ear rot, in corn, caused by Fusarium graminearum. Genome 2005, 48, 521-533.

123. Pè, M.E.; Gianfranceschi, L.; Taramino, G.; Tarchini, R.; Angelini, P.; Dani, M.; Binelli, G. Mapping quantitative trait loci (QTLs) for resistance to Gibberella zeae infection in maize Mol. Gen. Genet. 1993, 241, 11-16.

124. Reinprecht, Y.; Wu, X.; Yan, S.; Labey, L.; Dasilva, E.; Martin, J.C.; Pauls, K.P. A microarraybased approach for identifying genes for resistance to Fusarium graminearum in maize (Zea Mays L.) Cereal Res. Commun. 2008, 36, 253-259.

125. Dodds, P.N.; Lawrence, G.J.; Catanzariti, A.M.; Teh, T.; Wang, C.I.A.; Ayliffe, M.A.; Kobe, B.; Ellis, J.G. Direct protein interaction underlies gene-for-gene specificity and coevolution of the flax resistance genes and flax rust avirulence genes. Proc. Natl. Acad. Sci. USA 2006, 103, 8888-8893.

126. Zhang, G.; Mergoum, M. Molecular mapping of kernel shattering and its association with fusarium head blight resistance in a Sumai3 derived population. Theor. Appl. Genet. 2007, 115, 757-766.

127. Bai, G.H.; Plattner, R.; Desjardins, A.; Kolb, F. Resistance to fusarium head blight and deoxynivalenol accumulation in wheat. Plant Breed. 2001, 120, 1-6.

128. Geddes, J.; Eudes, F.; Tucker, J.R.; Legge, W.G.; Selinger, L.B. Evaluation of inoculation methods on infection and deoxynivalenol production by Fusarium graminearum on barley. Can. J. Plant Pathol. 2008, 30, 66-73.

129. Bruins, M.B.M.; Karsai, I.; Schepers, J.; Snijders, C.H.A. Phytotoxicity of deoxynivalenol to wheat tissue with regard to in vitro selection for fusarium head blight resistance. Plant Sci. 1993, 94, 195-206.

130. Fadel, F.; Wenzel, G. In vitro selection for tolerance to Fusarium in F-1 microspore populations of wheat. Plant Breed. 1993, 110, 89-95.

131. Eudes, F.; Comeau, A.; Rioux, S.; Collin, J. Trichothecene-mediated in vitro selection in wheat for reduced mycotoxin accumulation caused by Fusarium graminearum. Trichothecene-mediated in vitro selection in wheat for reduced mycotoxin accumulation caused by Fusarium graminearum 2008, In Press.

132. Campbell, M.A.; Fitzgerald, H.A.; Ronald, P.C. Engineering pathogen resistance in crop plants. Transgenic Res. 2002, 11, 599-613.

133. Dahleen, L.S.; Okubara, P.A.; Blechl, A.E. Transgenic approaches to combat fusarium head blight in wheat and barley. Crop Sci. 2001, 41, 628-637. 
134. Munkvold, G.P. Epidemiology of Fusarium diseases and their mycotoxins in maize ears. Eur. J. Plant Pathol. 2003, 109, 705-713.

135. Ehrlich, K.C.; Daigle, K.W. Protein Synthesis Inhibition by 8 Oxo-12 13-Epoxytrichothecenes. Biochim. Biophys. Acta 1987, 923, 206-213.

136. Kimura, M.; Kaneko, I.; Komiyama, M.; Takatsuki, A.; Koshino, H.; Yoneyama, K.; Yamaguchi, I. Trichothecene 3-O-acetyltransferase protects both the producing organism and transformed yeast from related mycotoxins. Cloning and characterization of Tri101. J. Biol. Chem. 1998, 273, 1654-1661.

137. Eriksen, G.S.; Pettersson, H.; Lundh, T. Comparative cytotoxicity of deoxynivalenol, nivalenol, their acetylated derivatives and de-epoxy metabolites. Food Chem. Toxicol. 2004, 42, 619-624.

138. Alexander, N.J. The TRI101 story: engineering wheat and barley to resist fusarium head blight. World Mycotoxin J. 2008, 1, 31-37.

139. Ohsato, S.; Ochiai, F.T.; Nishiuchi, T.; Takahashi, A.N.; Koizumi, S.; Hamamoto, H.; Kudo, T.; Yamaguchi, I.; Kimura, M. Transgenic rice plants expressing trichothecene 3-O-acetyltransferase show resistance to the Fusarium phytotoxin deoxynivalenol. Plant Cell Rep. 2007, 26, 531-538.

140. Okubara, P.A.; Blechl, A.E.; McCormick, S.P.; Alexander, N.J.; Dill, M.R.; Hohn, T.M. Engineering deoxynivalenol metabolism in wheat through the expression of a fungal trichothecene acetyltransferase gene. Theor. Appl. Genet. 2002, 106, 74-83.

141. Alexander, N.J.; McCormick, S.P.; Hohn, T.M. TRI12, a trichothecene efflux pump from Fusarium sporotrichioides: Gene isolation and expression in yeast. Mol. Gen. Genet. 1999, 261, 977-984.

142. Poppenberger, B.; Berthiller, F.; Lucyshyn, D.; Sieberer, T.; Schuhmacher, R.; Krska, R.; Kuchler, K.; Glossl, J.; Luschnig, C.; Adam, G. Detoxification of the Fusarium mycotoxin deoxynivalenol by a UDP-glucosyltransferase from Arabidopsis thaliana. J. Biol. Chem. 2003, 278, 47905-47914.

143. Berthiller, F.; Dall'Asta, C.; Schuhmacher, R.; Lemmens, M.; Adam, G.; Krska, R. Masked mycotoxins: Determination of a deoxynivalenol glucoside in artificially and naturally contaminated wheat by liquid chromatography-tandem mass spectrometry. J. Agric. Food Chem. 2005, 53, 3421-3425.

144. Dall’Asta, C.; Berthiller, F.; Schuhmacher, R.; Adam, G.; Lemmens, M.; Krska, R. DONglycosides: Characterisation of synthesis products and screening for their occurrence in DONtreated wheat samples. Mycotox. Res. 2005, 21, 123-127.

145. Lemmens, M.; Scholz, U.; Berthiller, F.; Dall'Asta, C.; Koutnik, A.; Schuhmacher, R.; Adam, G.; Bürstmayr, H.; Mesterházy, Á.; Krska, R.; Ruckenbauer, P. The ability to detoxify the mycotoxin deoxynivalenol colocalizes with a major quantitative trait locus for fusarium head blight resistance in wheat. Mol. Plant-Microbe Interact. 2005, 18, 1318-24.

146. Gareis, M.; Bauer, J.; Thiem, J.; Plank, G.; Grabley, S.; Gedek, B. Cleavage of zearalenoneglycoside, a masked mycotoxin, during digestion in swine. Zentralbl. Veterinarmed. B 1990, 37, 236-240.

147. Savard, M.E. Deoxynivalenol fatty acid and glucoside conjugates. J. Agric. Food Chem. 1991, 39, 570-574. 
148. Tanaka, T.; Yoneda, A.; Inoue, S.; Sugiura, Y.; Ueno, Y. Simultaneous determination of trichothecene mycotoxins and zearalenone in cereals by gas chromatography-mass spectrometry. J. Chromatogr. A 2000, 882, 23-28.

149. Krska, R.; Baumgartner, S.; Josephs, R. The state-of-the-art in analysis of type-A and -B trichothecene mycotoxins in cereals. Fresenius J. Anal. Chem. 2001, 371, 285-299.

150. Berthiller, F.; Schuhmacher, R.; Buttinger, G.; Krska, R. Rapid simultaneous determination of major type A- and B-trichothecenes as well as zearalenone in maize by high performance liquid chromatography-tandem mass spectrometry. J. Chromatogr. A 2005, 1062, 209-216.

151. Krska, R.; Welzig, E.; Berthiller, F.; Molinelli, A.; Mizaikoff, B. Advances in the analysis of mycotoxins and its quality assurance. Food Addit. Contam. 2005, 22, 345-353.

152. Zöllner, P.; Mayer-Helm, B. 2006. Trace mycotoxin analysis in complex biological and food matrices by liquid chromatography-atmospheric pressure ionisation mass spectrometry. $J$. Chromatogr. A 2006, 1136, 123-169

153. Krska, R.; Welzig, E.; Boudra, H. Analysis of Fusarium toxins in feed. Anim. Feed Sci. Technol. 2007, 137, 241-264.

154. Beremand, M.N. Isolation and characterization of mutants blocked in T-2 toxin biosynthesis. Appl. Environ. Microbiol. 1987, 53, 1855-1859.

155. Beremand, M.N.; Desjardins, A.E. Trichothecene biosynthesis in Gibberella pulicaris: Inheritance of C-8 hydroxylation. J. Indus. Microbiol. 1989, 3, 167-174.

156. Meek, I.B.; Peplow, A.W.; Ake, C., Jr.; Phillips, T.D.; Beremand, M.N. Tri1 encodes the cytochrome P450 monooxygenase for C-8 hydroxylation during trichothecene biosynthesis in Fusarium sporotrichioides and resides upstream of another new Tri gene. Appl. Environ. Microbiol. 2003, 69, 1607-1613.

157. Tokai, T.; Koshino, H.; Takahashi, A.N.; Sato, M.; Fujimura, M.; Kimura, M. Fusarium Tri4 encodes a key multifunctional cytochrome P450 monooxygenase for four consecutive oxygenation steps in trichothecene biosynthesis. Biochem. Biophys. Res. Commun. 2007, 353, 412-417.

158. Hohn, T.M.; Beremand, P.D. Isolation and nucleotide sequence of a sesquiterpene cyclase gene from the trichothecene-producing fungus Fusarium sporotrichioides. Gene 1989, 79, 131-138.

159. McCormick, S.P.; Alexander, N.J. Fusarium Tri8 encodes a trichothecene C-3 esterase. Appl. Environ. Microbiol. 2002, 68, 2959-2964.

160. McCormick, S.P.; Hohn, T.M. Accumulation of trichothecenes in liquid cultures of a Fusarium sporotrichioides mutant lacking a functional trichothecene C-15 hydroxylase. Appl. Environ. Microbiol. 1997, 63, 1685-1688.

161. Kim, H.S.; Lee, T.; Dawlatana, M.; Yun, S.H.; Lee, Y.W. Polymorphism of trichothecene biosynthesis genes in deoxynivalenol- and nivalenol-producing Fusarium graminearum isolates. Mycol. Res. 2003, 107, 190-197.

162. Peplow, A.W.; Meek, I.B.; Wiles, M.C.; Phillips, T.D.; Beremand, M.N. Tri16 is required for esterification of position C-8 during trichothecene mycotoxin production by Fusarium sporotrichioides. Appl. Environ. Microbiol. 2003, 69, 5935-5940.

163. Kimura, M.; Tokai, T.; O'Donnell, K.; Ward, T.J.; Fujimura, M.; Hamamoto, H.; Shibata, T.; Yamaguchi, I. The trichothecene biosynthesis gene cluster of Fusarium graminearum F15 
contains a limited number of essential pathway genes and expressed non-essential genes. FEBS Lett. 2003, 539, 105-110.

164. Proctor, R.H.; Hohn, T.M.; McCormick, S.P.; Desjardins, A.E. Tri6 encodes an unusual zinc finger protein involved in regulation of trichothecene biosynthesis in Fusarium sporotrichioides. Appl. Environ. Microbiol. 1995, 61, 1923-1930.

165. Hohn, T.M.; Krishna, R.; Proctor, R.H. Characterization of a transcriptional activator controlling trichothecene toxin biosynthesis. Fungal Genet. Biol. 1999, 26, 224-235.

166. Tag, A.G.; Garifullina, G.F.; Peplow, A.W.; Ake, C., Jr.; Phillips, T.D.; Hohn, T.M.; Beremand, M.N. A novel regulatory gene, Tri10, controls trichothecene toxin production and gene expression. Appl. Environ. Microbiol. 2001, 67, 5294-5302.

167. Alexander, N.J.; Hohn, T.M.; McCormick, S.P. Molecular characterization of TRI12 which encodes an apparent transport protein involved in trichothecene production by Fusarium sporotrichioides. Cereal Res. Commun. 1997, 25, 347-348.

168. Brown, D.W.; Dyer, R.B.; McCormick, S.P.; Kendra, D.F.; Plattner, R.D. Functional demarcation of the Fusarium core trichothecene gene cluster. Fungal Genet. Biol. 2004, 41, 454462.

169. Hohn, T.M.; McCormick, S.P.; Desjardins, A.E. Evidence for a gene cluster involving trichothecene-pathway biosynthetic genes in Fusarium sporotrichioides. Curr. Genet. 1993, 24, 291-295.

170. Kimura, M.; Tokai, T.; Takahashi, A.N.; Ohsato, S.; Fujimura, M. Molecular and genetic studies of Fusarium trichothecene biosynthesis: Pathways, genes, and evolution. Biosci. Biotechnol. Biochem. 2007, 71, 2105-2123.

171. Ward, T.J.; Bielawski, J.P.; Kistler, H.C.; Sullivan, E.; O'Donnell, K. Ancestral polymorphism and adaptive evolution in the trichothecene mycotoxin gene cluster of phytopathogenic Fusarium. Proc. Natl. Acad. Sci. USA 2002, 99, 9278-9283.

172. McCormick, S.P. The role of DON in pathogenicity. In Fusarium Head Blight of Wheat and Barley; Leonard, K.J., Bushnell, W.R., Eds.; The American Phytopathological Society: St. Paul, Minnesota, USA, 2003; Chapter 7, pp. 165-183.

173. Gottschalk, C.; Barthel, J.; Engelhardt, G.; Bauer, J.; Meyer, K. Occurrence of type A trichothecenes in conventionally and organically produced oats and oat products. Mol. Nutr. Food Res. 2007, 51, 1547-1553.

174. Brown, D.W.; Proctor, R.H.; Dyer, R.B.; Plattner, R.D. Characterization of a Fusarium 2-gene cluster involved in trichothecene C-8 modification. J. Agric. Food Chem. 2003, 51, 7936-7944.

175. McCormick, S.P.; Alexander, N.J.; Proctor, R.H. Heterologous expression of two trichothecene P450 genes in Fusarium verticillioeds. Can. J. Microbiol. 2006, 52, 220-226.

(C) 2009 by the authors; licensee Molecular Diversity Preservation International, Basel, Switzerland. This article is an open-access article distributed under the terms and conditions of the Creative Commons Attribution license (http://creativecommons.org/licenses/by/3.0/). 